\title{
The Non-Recurrent Laryngeal Nerve: a meta-analysis and clinical considerations
}

\author{
Brandon Michael Henry ${ }^{\text {Corresp., }}{ }^{1,2}$ ， Silvia Sanna ${ }^{3}$ ， Matthew J Graves ${ }^{1,2}$ ， Jens Vikse ${ }^{2,4}$, Beatrice Sanna ${ }^{5}$, Iwona \\ M. Tomaszewska ${ }^{6}$, R. Shane Tubbs ${ }^{7}$, Jerzy A Walocha ${ }^{1,2}$, Krzysztof A Tomaszewski ${ }^{1,2}$ \\ ${ }^{1}$ Department of Anatomy, Jagiellonian University Medical College, Kraków, Poland \\ 2 International Evidence-Based Anatomy Working Group, Kraków, Poland \\ 3 Department of Surgical Sciences, University of Cagliari, Monserrato, Sardinia, Italy \\ 4 Division of Medicine, Stavanger University Hospital, Stavanger, Norway \\ 5 Faculty of Medicine and Surgery, University of Cagliari, Monserrato, Sardinia, Italy \\ 6 Department of Medical Education, Jagiellonian University Medical College, Krakow, Poland \\ 7 Seattle Science Foundation, Seattle, Washington, United States \\ Corresponding Author: Brandon Michael Henry \\ Email address: bmhenry55@gmail.com
}

Background. The Non-Recurrent Laryngeal Nerve (NRLN) is a rare embryologically-derived variant of the Recurrent Laryngeal Nerve (RLN). The presence of a NRLN significantly increases the risk of iatrogenic injury and operative complications. Our aim was to provide a comprehensive meta-analysis of the overall prevalence of the NRLN, its origin, and its association with an aberrant subclavian artery.

Methods. Through March 2016, a database search was performed of PubMed, CNKI, ScienceDirect, EMBASE, BIOSIS, SciELO, and Web of Science. The references in the included articles were also extensively searched. At least two reviewers judged eligibility and assessed and extracted articles. MetaXL was used for analysis, with all pooled prevalence rates calculated using a random effects model. Heterogeneity among the included studies was assessed using the Chi ${ }^{2}$ test and the $\mathrm{I}^{2}$ statistic.

Results. Fifty-three studies (33,571 right RLNs) reported data on the prevalence of a right NRLN. The pooled prevalence estimate was $0.7 \%(95 \% \mathrm{Cl}: 0.6-0.9)$. The NRLN was found to originate from the vagus nerve at or above the laryngotracheal junction in $58.3 \%$ and below it in $41.7 \%$. A right NRLN was associated with an aberrant subclavian artery in $86.7 \%$ of cases.

Conclusion. The NRLN is a rare yet very clinically relevant structure for surgeons and is associated with increased risk of iatrogenic injury, most often leading to temporary or permanent vocal cord paralysis. A thorough understanding of the prevalence, origin, and associated pathologies is vital for preventing injuries and complications. 


\section{The Non-Recurrent Laryngeal Nerve: a meta-analysis and clinical considerations}

2

3 Running Title: Non-Recurrent Laryngeal Nerve: A Review

5 Brandon Michael Henry ${ }^{1,2}$, Silvia Sanna ${ }^{3}$, Matthew J. Graves ${ }^{1,2}$, Jens Vikse ${ }^{1,7}$, Beatrice Sanna ${ }^{4}$,

6 Iwona M. Tomaszewska ${ }^{5}$, R. Shane Tubbs ${ }^{6}$, Jerzy A. Walocha ${ }^{1,2}$, Krzysztof A. Tomaszewski ${ }^{1,2}$

$9 \quad{ }^{1}$ International Evidence-Based Anatomy Working Group, Krakow, Poland

${ }^{2}$ Department of Anatomy, Jagiellonian University Medical College, Krakow, Poland

${ }^{3}$ Department of Surgical Sciences, University of Cagliari, Sardinia, Italy

${ }^{4}$ Faculty of Medicine and Surgery, University of Cagliari, Sardinia, Italy

${ }^{5}$ Department of Medical Education, Jagiellonian University Medical College, Krakow, Poland

$14{ }^{6}$ Seattle Science Foundation, Seattle, Washington

${ }^{7}$ Division of Medicine, Stavanger University Hospital, Stavanger, Norway

Corresponding Author:

Brandon Michael Henry, M.D.

21 Department of Anatomy, Jagiellonian University Medical College

2212 Kopernika St, 31-034 Krakow, Poland

23 e-mail: bmhenry55@gmail.com 


\section{ABSTRACT}

25 Background. The Non-Recurrent Laryngeal Nerve (NRLN) is a rare embryologically-derived 26 variant of the Recurrent Laryngeal Nerve (RLN). The presence of a NRLN significantly increases

27 the risk of iatrogenic injury and operative complications. Our aim was to provide a comprehensive 28 meta-analysis of the overall prevalence of the NRLN, its origin, and its association with an aberrant 29 subclavian artery.

30 Methods. Through March 2016, a database search was performed of PubMed, CNKI, 31 ScienceDirect, EMBASE, BIOSIS, SciELO, and Web of Science. The references in the included 32 articles were also extensively searched. At least two reviewers judged eligibility and assessed and extracted articles. MetaXL was used for analysis, with all pooled prevalence rates calculated using a random effects model. Heterogeneity among the included studies was assessed using the $\mathrm{Chi}^{2}$ test and the $\mathrm{I}^{2}$ statistic.

Results. Fifty-three studies (33,571 right RLNs) reported data on the prevalence of a right NRLN.

37 The pooled prevalence estimate was $0.7 \%$ (95\%CI: $0.6-0.9)$. The NRLN was found to originate 38 from the vagus nerve at or above the laryngotracheal junction in $58.3 \%$ and below it in $41.7 \%$. A 39 right NRLN was associated with an aberrant subclavian artery in $86.7 \%$ of cases.

Conclusion. The NRLN is a rare yet very clinically relevant structure for surgeons and is associated with increased risk of iatrogenic injury, most often leading to temporary or permanent vocal cord paralysis. A thorough understanding of the prevalence, origin, and associated pathologies is vital for preventing injuries and complications. 


\section{INTRODUCTION}

47 The Non-Recurrent Laryngeal Nerve (NRLN) is a rare variant of the Recurrent Laryngeal Nerve

48 (RLN) that takes an aberrant course, not descending into the thorax as is usual (Figure 1). It was

49 first reported by Stedman in 1823 (Stedman, 1823). It arises almost exclusively on the right side

50 and is closely associated with vascular anomalies of the aortic arch (Wang et al., 2011). On the

51 right side, the NRLN usually results from partial regression of the fourth pharyngeal arch, resulting

52 in an aberrant subclavian artery (arteria lusoria) that runs behind the esophagus (Figure 1B) (Wang

53 et al., 2011). This atypical vascular pattern permits the nerve to migrate freely into the neck as the

54 fetus grows longitudinally (Wang et al., 2011). The existence of a NRLN without the associated

55 vascular anomalies has no clear embryological explanation (Wang et al., 2011). NRLNs on the left

56 side have only been reported a few times, all of them accompanied by other significant pathologies

57 such as situs inversus (Henry et al., 1988; Toniato et al., 2004; Hong, Park \& Yang, 2014).

58 The NRLN variant of the RLN is a major risk factor for iatrogenic injury and can lead to

59 detrimental postoperative complications if its existence is not observed in a timely fashion. As

60 noted by Toniato (2004), patients experienced a nearly six-fold increase in intraoperative nerve

61 injuries if they had an undetected NRLN (Toniato et al., 2004). A thorough dissection in all

62 approaches to thyroidectomy, parathyroidectomy, and endarterectomy is essential for identifying

63 the neurovascular structures and preventing intra- and post-operative nerve complications, the

64 most common of which is vocal cord paralysis (De Luca et al., 2000; Hong, Park \& Yang, 2014).

65 It was noted in Iacobone (2015) that preoperative ultrasonography (USG) to assess patients for a

66 NRLN was extremely successful, with an accuracy of more than 98\% (Iacobone et al., 2015). It is

67 therefore strongly suggested that measures such as preoperative USG are taken to identify these

68 variant structures because they clearly help to prevent injury. In Iacobone's study nerve palsy did 
69 not arise in the ultrasound group yet arose 3 times in the control group, a true testament to the 70 importance of preoperative identification (Iacobone et al., 2015).

71 The prevalence of the NRLN has been reported numerous times with rates ranging from $0 \%$ to

72 4.76\% (Menck, Grüber \& Lierse, 1990; Freschi et al., 1994; Moreau et al., 1998; Sasou, Nakamura

73 \& Kurihara, 1998; Sturniolo et al., 1999; Monfared, Gorti \& Kim, 2002; Page, Foulon \& Strunski,

74 2003; Makay et al., 2008; Lee et al., 2009; Kandil et al., 2011; Benouaich et al., 2012; Ngo Nyeki

75 et al., 2015). It is essential to obtain accurate anatomical data on the NRLN if patients with this

76 anomaly are to be assessed properly for surgical candidacy and operative planning. The aim of our

77 analysis was to provide a comprehensive and evidence-based assessment of the prevalence of the

78 NRLN. We also aimed to investigate the course-related consequences of the different types of 79 NRLN, and the association of this variant nerve with the incidence of an aberrant subclavian artery.

80 Since the RLN, and in particular the NRLN, are particularly susceptible to surgical injury, a 81 complete understanding and assessment of their variant anatomy is essential for preventing injuries 82 and ensuring complication-free procedures. 


\section{METHODS}

\section{Search strategy}

86 Through March 2016, a database search was performed of PubMed, CNKI, ScienceDirect, 87 EMBASE, BIOSIS, SciELO, and Web of Science in order to identify eligible articles for the meta88 analysis. The exhaustive search strategy employed for PubMed is presented in Supporting Table

89 1. No date limits or language restrictions were applied. The references in the included articles were 90 also extensively searched. The Preferred Reporting Items for Systematic Reviews and Meta91 Analyses (PRISMA) guidelines were strictly followed throughout this meta-analysis (Supporting 92 Table 2) (Moher et al., 2009). We prospectively registered the meta-analysis in PROSPERO 93 (CRD42015026096).

\section{Criteria for Study Selection}

95 Studies were considered eligible for inclusion in the meta-analysis if they: (1) reported clear, 96 extractable prevalence data on the non-recurrent laryngeal nerve with respect to side and (2) were 97 cadaveric, intraoperative, or imaging studies. The exclusion criteria included: (1) case studies, case reports, conference abstracts, and letters to the editor; (2) studies reporting incomplete data (i.e. not reporting rates with respect to side); and (3) studies on patients with trauma to the head and neck region. The decision to include only articles reporting rates with respect to side was based on the previously-established difference in prevalence rates of the NRLN between the right and the left sides (Henry et al., 1988).

All studies were independently assessed for eligibility by three reviewers (S.S., J.V., and B.S.). Any disparities arising during the assessment were resolved by a consensus among all the reviewers, after consulting with the authors of the original study, if possible. All full-text articles published in languages not spoken fluently by the authors were translated for further eligibility 
107 assessment by medical professionals fluent in both English and the original language of the 108 manuscript.

\section{Data extraction}

110 Data were independently extracted from the included articles by two independent reviewers (S.S. 111 and J.V.). These data included demographic information such as year, country, type of study, study 112 design, and number of nerves. The primary outcome, the prevalence of right and left NRLNs was 113 isolated. Secondary outcomes such as the level of origin of the NRLN from the vagus nerve (at or 114 above the level of the laryngotracheal junction OR below that level) (Figure 2), and the prevalence 115 of an aberrant subclavian artery when a NRLN was present were also noted when available. In the 116 event of data inconsistencies, the reviewers attempted to contact the authors of the original study 117 by email for clarification.

\section{Statistical analysis}

119 Statistical analysis was performed by B.M.H. and M.G. using MetaXL version 2.0 by EpiGear 120 International Pty Ltd (Wilston, Queensland, Australia). All pooled prevalence rates were 121 calculated using a random effects model (Henry, Tomaszewski \& Walocha, 2016). The Chi ${ }^{2}$ test 122 and the $\mathrm{I}^{2}$ statistic were used to measure the level of heterogeneity among the included studies. For 123 the $\mathrm{Chi}^{2}$ test, a Cochran's Q p-value of $<0.10$ indicated significant heterogeneity (Higgins \& Green, 124 2011). The values of the $I^{2}$ statistic were interpreted as follows: $0-40 \%$ might not be important; $12530-60 \%$ could indicate moderate heterogeneity; 50-90\% could indicate substantial heterogeneity; 126 and $75-100 \%$ indicated considerable heterogeneity (Higgins \& Green, 2011).

127 To probe the etiology of heterogeneity, subgroup analysis was performed on the basis of type of 128 study (cadaveric vs. intraoperative), study design (prospective vs. retrospective), and geographical 
129 origin of the articles. Significant differences between subgroups were judged from the confidence 130 intervals of the rates, any overlap between groups indicating a lack of statistical significance 131 (Henry, Tomaszewski \& Walocha, 2016). Furthermore, a leave-one-out sensitivity analysis was 132 performed to explore the source of heterogeneity. 


\section{RESULTS}

\section{Study Identification}

136 Figure 3 presents an overview of the flow of studies in the meta-analysis. Through database 137 searching, 2,795 initial articles were identified. A further 84 articles were identified from reference 138 searching. After removing duplicates and primary screening, 328 articles were assessed by full 139 text for eligibility in the meta-analysis. Of these, 53 were deemed eligible and included, while 275 140 were excluded, 21 for not reporting extractable NRLN rates with respect to side.

142 Characteristics of Included Studies

143 The characteristics of the studies included in the meta-analysis are summarized in Table 1, along 144 with the reported prevalence of a right NRLN. A total of 53 studies $(n=53,577$ total nerves;

145 33,571 Right RLNs and 20,006 Left RLNs) were included: 35 intraoperative, 17 cadaveric and 1 146 imaging (CT) (Reed, 1943; Wade, 1955; Hunt, Poole \& Reeve, 1968; Stewart, Mountain \&

147 Colcock, 1972; Skandalakis et al., 1976; Papadatos, 1978; Proye et al., 1982; Flament, Delattre 148 \& Palot, 1983; Henry et al., 1988; Menck, Grüber \& Lierse, 1990; Lekacos et al., 1992; Freschi 149 et al., 1994; Moreau et al., 1998; Sasou, Nakamura \& Kurihara, 1998; Sturniolo et al., 1999; 150 Campos \& Henriques, 2000; Raffaelli, Iacobone \& Henry, 2000; Watanabe et al., 2001, 2016a; 151 Monfared, Gorti \& Kim, 2002; Page, Foulon \& Strunski, 2003; Hermans et al., 2003; Ardito et 152 al., 2004; Toniato et al., 2004; Spartà et al., 2004; Sciumè et al., 2005; Shindo, Wu \& Park, 2005; 153 Beneragama \& Serpell, 2006; Maranillo et al., 2008; Makay et al., 2008; Serpell, Yeung \&

154 Grodski, 2009; Lee et al., 2009; Sunanda, Tilakeratne \& De Silva, 2010; Shao et al., 2010; Wang 155 et al., 2011; Kaisha, Wobenjo \& Saidi, 2011; Kandil et al., 2011; Pradeep, Jayashree \& Harshita, 156 2012; Chiang et al., 2012; Tang et al., 2012; Benouaich et al., 2012; Asgharpour et al., 2012; 
157 Silva, Siqueira \& Arruda, 2013; Donatini, Carnaille \& Dionigi, 2013; Satoh et al., 2013; Cai et

158 al., 2013; Hong, Park \& Yang, 2014; Yang et al., 2014; Han, Bai \& Lu, 2015; Dolezel et al.,

159 2015; Iacobone et al., 2015; Buła et al., 2015; Ngo Nyeki et al., 2015; Barczyński et al., 2015).

160 The dates of the included studies spanned the period from 1943 to 2016 . Their geographical

161 distribution was extremely wide, the most substantial contributions coming from Europe (27

162 studies) and Asia (15 studies).

163

164 Prevalence of a Right NRLN

165 A total of 53 studies $(33,571$ right RLNs) reported data on the prevalence of a right NRLN. The 166 overall pooled prevalence estimate in the general population was $0.7 \%$ [95\%CI: $0.6-0.9 ; \mathrm{I}^{2}=42.5$ 167 (95\%CI: 20.2-58.6); $\mathrm{p}=0.001]$ (Figure 4).

168 In subgroup analysis, the pooled prevalence of a right NRLN was significantly higher in cadaveric 169 (1.4\%, 95\%CI: 0.9-2.0) than intraoperative (0.7\%, 95\%CI: 0.5-0.8) studies (Table 2). Subgroup 170 analysis by geographical origin revealed no significant differences (Table 3), and no significant 171 differences were detected in the leave-one-out sensitivity analysis.

\section{Types of Right NRLN}

174 A total of 14 studies ( $\mathrm{n}=81$ right NRLNs) reported extractable data on the type of NRLN with 175 respect to its level of origin from the vagus nerve. In 58.3\% (95\%CI: $36.1-79.0)$ of cases, the 176 NRLN originated at or above the level of the laryngotracheal junction, while in $41.7 \%(95 \% \mathrm{CI}$ : $17721.0-63.9)$ it originated below that level ( $\left.\mathrm{I}^{2}=67.6 \%, 95 \% \mathrm{CI}: 43.4-81.4 ; \mathrm{p}<0.001\right)$. 
180 In 21 studies with right NRLNs ( $\mathrm{n}=136$ nerves), an aberrant subclavian artery was reported. An 181 aberrant subclavian artery was present in $89.3 \%(95 \% \mathrm{CI}: 79.6-96.3)$ of cases $\left(\mathrm{I}^{2}=49.1 \%, 95 \% \mathrm{CI}\right.$ : $182 \quad 15.7-69.3 ; \mathrm{p}=0.006)$.

183

\section{Prevalence of a Left NRLN}

185 A total of 41 studies with left RLNs $(n=20,006)$ reported data on the prevalence of a left NRLN. 186 Only one of the included studies, by Henry in 1988, reported the presence of left NRLNs (two 187 cases, both in patients with situs inversus), which equated to a pooled prevalence estimate of $0 \%$ 188 (95\%CI: 0-0.1; $\left.\mathrm{I}^{2}=0 \%, \mathrm{p}=1.0\right)$ (Henry et al., 1988). 


\section{DISCUSSION}

191 The NRLN, a rare, often developmentally-derived variant of the RLN, most often results from

192 partial failure of the pharyngeal apparatus during embryo development (Watanabe et al., 2016b).

193 A NRLN can very easily be injured surgically and this leads to long-term postoperative 194 complications such as vocal cord paralysis. Adequate identification and isolation is most important 195 for preventing injury (Toniato et al., 2004). The frequency of NRLN injury remains poorly 196 reported, vague, and believed to be continually underestimated (Dolezel et al., 2015).

197 The pooled prevalence rates of NRLN were calculated solely from studies that provided 198 information about the rate per side in patients or cadavers. No NRLN has ever been noted on the 199 left side in the absence of rare pathologies such as situs inversus with accompanying aortic arch 200 abnormalities (Toniato et al., 2004; Hong, Park \& Yang, 2014). To include studies that mixed right 201 and left sides into one rate would dilute and thereby falsify the overall pooled prevalence rates. 202 We therefore infer that the best representation of overall NRLN prevalence is its existence on the 203 right side. Thus, the pooled prevalence estimate of a right-sided NRLN is a proxy of the pooled

204 prevalence estimate of NRLN per person/cadaver. In support of our decision to include only 205 studies that reported rates per side, we calculated the prevalence of left NRLNs on the basis of 206 literature data. The prevalence was $0 \%$ in a sample of 20,006 left nerves examined, indicating that 207 this anomaly occurs in $<0.1 \%$ of the population.

208 We found an overall pooled prevalence of right NRLN of $0.7 \%$ in the general population. 209 Subgroup analysis based on study modality revealed significant differences, NRLNs being found 210 more than twice as often in cadavers as in operative subjects. We should note that because of such 211 limitations in the intraoperative viewing of anatomical structures as equipment obstruction, edema, 212 inflammation, and small caliber of nerve branches, the cadaveric rate $(1.4 \%)$ could reflect the 
213 NRLN's true prevalence better. However, the cadaveric group (1,700 nerves) was limited by its

214 small sample size, dwarfed by the intraoperative group (31,277 nerves). Further subgroup analysis

215 based on geographical origin of the study revealed no notable differences among populations.

216 A subanalysis of variant nerves allowed the types of origin of the NRLN to be assessed on the basis

217 of whether they lay above or below the laryngotracheal junction (LTJ); the prevalence values were

$21858.3 \%$ and $41.7 \%$, respectively. Many previous articles have developed classification systems for

219 NRLN origins, but very few have used the same system, the majority just describing the NRLNs

220 identified (Stewart, Mountain \& Colcock, 1972; Henry et al., 1988; Toniato et al., 2004; Chiang

221 et al., 2012; Hong, Park \& Yang, 2014; Dolezel et al., 2015). However, the nerves differed in their

222 courses despite originating from similar levels on the vagus nerve. Some NRLNs exhibited a 223 course in which the nerve immediately tracks medially and enters the larynx. As described in the 224 study by Toniato et al., most patients with NRLNs who experienced injuries in their series had 225 nerves that originated above the LTJ and coursed with the superior thyroid artery (Toniato et al., 226 2004). Another subset of patients had NRLNs originating above the LTJ but displaying a looping course, where after originating they descended inferiorly and then reascended superiorly before entering the larynx (Figure 5) (Toniato et al., 2004; Hong, Park \& Yang, 2014).

The prevalence of a right NRLN was strongly associated with the presence of aberrant subclavian artery, the causative anomaly of Dysphagia Lusoria (Bayford-Autenrieth Dysphagia) (Watanabe et al., 2001). The symptoms associated with an aberrant subclavian artery are very often silent, but 232 if present can include dysphagia, chronic cough, and unexplained ischemia of the right upper limb 233 (Natsis et al., 2015). We noted that $86.7 \%$ of right NRLN patients had an aberrant subclavian artery 234 pattern. The embryological pathogenesis of a NRLN with an aberrant subclavian artery is clear and understood, but the presence of the variant nerve without the accompanying vascular anomaly 
236 remains a mystery (Dolezel et al., 2015). Wang et al. noted, along with the research by Raffaelli

237 et al., that the origin of the NRLN was never confirmed to be the vagus in these non-aberrant

238 subclavian artery cases (Raffaelli, Iacobone \& Henry, 2000; Wang et al., 2011). It is posited that

239 the connecting branches between the sympathetic trunk and normal RLN could be mistaken for a

240 NRLN (Raffaelli, Iacobone \& Henry, 2000).

241 Preoperative identification of aberrant subclavian arteries and NRLNs is the best defense for a

242 surgeon. As was noted by Iacobone for USG and Watanabe for Computed Tomography (CT),

243 identification of these variant structures is potentially $100 \%$ of the time by using these imaging

244 techniques (Iacobone et al., 2015; Watanabe et al., 2016a). Another option for identification

245 intraoperatively is the use of nerve monitoring (IONM) techniques. Dolezel reports that the use of

246 IONM increased the prevalence of NRLNs yet decreased the incidence of postoperative nerve

247 palsy (Dolezel et al., 2015). The use of IONM is particularly advantageous when patients have an

248 underlying pathology which may restrict surgical dissection and viewability of the neural

249 structures (Barczyński et al., 2014). The IONM technology is continually becoming more

250 advanced and provides a promising tool for use in future procedures.

251 Additional research on this topic is necessary to assess the possible etiologies of the NRLN when

252 it occurs in the absence of an aberrant subclavian artery. Furthermore, morphometric analysis of

253 the NRLN with regard to its origin and course would provide useful insight into its behavior and

254 enable its location to predicted more readily for operative planning. Nonetheless, since the variant

255 occurs in nearly $1 \%$ of the population and is associated with a high risk of iatrogenic injury, we

256 recommend preoperative USG examination for all patients undergoing procedures in the anterior 257 neck.

258 This study was limited by several facets, particularly, several studies were omitted from the meta- 
259 analysis due to the lack of reported data on the side of occurrence of the NRLN. Moreover, 260 although we performed detailed subgroup investigations, high levels of heterogeneity lingered 261 between the included studies. We suspect that this is because of inherent variability in the 262 occurrence of the NRLN. Lastly, no quality and risk-of-bias assessment of included studies was 263 performed due to a lack of an available tool for the field of anatomy. 


\section{CONCLUSIONS}

268 The NRLN is an asymptomatic and most often embryologically-derived variant of the RLN in

269 which the nerve arises directly from the vagus at a cervical level. In healthy patients the anomaly 270 is restricted to the right side and, if present, is a very clinically relevant structure, particularly for 271 surgeons conducting procedures directly or requiring access to the anterior neck. Non-Recurrent 272 Laryngeal Nerves are associated with increased risks for iatrogenic surgical injury, most often 273 leading to either temporary or permanent vocal cord paralysis. While a NRLN occurs in only about $2741 \%$ of the population, the high risk of iatrogenic injury indicates that its possible occurrence in a 275 patient should be screened preoperatively using USG. A thorough and complete understanding of 276 the prevalence, origin, and associated pathologies is vital for preventing injuries and for ensuring 277 patient safety and operative success.

278

279 ACKNOWLEDGEMENTS

280 Krzysztof A. Tomaszewski was supported by the Foundation for Polish Science (FNP).

281 We wish to thank Karolina Saganiak for the anatomical drawings used in this manuscript. 


\section{REFERENCES}

284

285

286

287

288

289

290

291

292

293

294

295

296

297

298

299

300

301

302

303

304

305

306

307

308

309

310

311

312

313

314

315

316

317

318

319

320

321

322

323

324

Ardito G., Revelli L., D’Alatri L., Lerro V., Guidi ML., Ardito F. 2004. Revisited anatomy of the recurrent laryngeal nerves. American journal of surgery 187:249-53.

Asgharpour E., Maranillo E., Sañudo J., Pascual-Font A., Rodriguez-Niedenführ M., Valderrama FJ., Viejo F., Parkin IG., Vázquez T. 2012. Recurrent laryngeal nerve landmarks revisited. Head \& neck $34: 1240-6$.

Barczyński M., Konturek A., Pragacz K., Papier A., Stopa M., Nowak W. 2014. Intraoperative nerve monitoring can reduce prevalence of recurrent laryngeal nerve injury in thyroid reoperations: results of a retrospective cohort study. World journal of surgery 38:599-606.

Barczyński M., Stopa M., Konturek A., Nowak W. 2015. The Overwhelming Majority but not All Motor Fibers of the Bifid Recurrent Laryngeal Nerve are Located in the Anterior Extralaryngeal Branch. World journal of surgery.

Beneragama T., Serpell JW. 2006. Extralaryngeal bifurcation of the recurrent laryngeal nerve: a common variation. ANZ journal of surgery 76:928-31.

Benouaich V., Porterie J., Bouali O., Moscovici J., Lopez R. 2012. Anatomical basis of the risk of injury to the right laryngeal recurrent nerve during thoracic surgery. Surgical and radiologic anatomy: SRA 34:509-12.

Buła G., Mucha R., Paliga M., Koziołek H., Niedzielski Z., Gawrychowski J. 2015. Non-Recurrent Laryngeal Nerve. Polski przeglad chirurgiczny 87:336-9.

Cai Q., Guan Z., Huang X., Yuan J., Pan Y., Zheng Y., Liang M., Fan S. 2013. The usefulness of preoperative computed tomography and intraoperative neuromonitoring identification of the nonrecurrent inferior laryngeal nerve. European archives of oto-rhino-laryngology : official journal of the European Federation of Oto-Rhino-Laryngological Societies (EUFOS) : affiliated with the German Society for Oto-Rhino-Laryngology - Head and Neck Surgery 270:2135-40.

Campos BA., Henriques PR. 2000. Relationship between the recurrent laryngeal nerve and the inferior thyroid artery: a study in corpses. Revista do Hospital das Clínicas 55:195-200.

Chiang F-Y., Lu I-C., Tsai C-J., Hsiao P-J., Lee K-W., Wu C-W. 2012. Detecting and identifying nonrecurrent laryngeal nerve with the application of intraoperative neuromonitoring during thyroid and parathyroid operation. American journal of otolaryngology 33:1-5.

Dolezel R., Jarosek J., Hana L., Ryska M. 2015. Clinical relevance and surgical anatomy of non-recurrent laryngeal nerve: 7 year experience. Surgical and radiologic anatomy: SRA 37:321-5.

Donatini G., Carnaille B., Dionigi G. 2013. Increased detection of non-recurrent inferior laryngeal nerve (NRLN) during thyroid surgery using systematic intraoperative neuromonitoring (IONM). World journal of surgery 37:91-3.

Flament JB., Delattre JF., Palot JP. 1983. [Anatomic pitfalls of recurrent laryngeal nerve dissection]. Journal de chirurgie 120:329-33.

Freschi G., Masi C., Pichi Graziani M., Pacifico G., Panconesi R., Corsi A., Seghi P. 1994. [Anatomic and surgical considerations regarding the recurrent laryngeal nerve in thyroidectomy]. Minerva chirurgica 49:943-7.

Han G., Bai X., Lu Z. 2015. Anatomical Technique and Clinical Significance of the Non-recurrent Laryngeal Nerve in Thyroid Surgery. Chinese General Practice 18:339-341.

Henry JF., Audiffret J., Denizot A., Plan M. 1988. The nonrecurrent inferior laryngeal nerve: review of 33 
325

326

327

328

329

330

331

332

333

334

335

336

337

338

339

340

341

342

343

344

345

346

347

348

349

350

351

352

353

354

355

356

357

358

359

360

361

362

363

364

365

cases, including two on the left side. Surgery 104:977-84.

Henry BM., Tomaszewski KA., Walocha JA. 2016. Methods of Evidence-Based Anatomy: a guide to conducting systematic reviews and meta-analysis of anatomical studies. Annals of Anatomy. DOI: 10.1016/j.aanat.2015.12.002.

Hermans R., Dewandel P., Debruyne F., Delaere PR. 2003. Arteria lusoria identified on preoperative CT and nonrecurrent inferior laryngeal nerve during thyroidectomy: a retrospective study. Head \& neck 25:113-7.

Higgins J., Green S. (eds.) 2011. Cochrane Handbook for Systematic Reviews of Interventions. The Cochrane Collaboration.

Hong KH., Park HT., Yang YS. 2014. Characteristic travelling patterns of non-recurrent laryngeal nerves. The Journal of laryngology and otology 128:534-9.

Hunt PS., Poole M., Reeve TS. 1968. A reappraisal of the surgical anatomy of the thyroid and parathyroid glands. The British journal of surgery 55:63-6.

Iacobone M., Citton M., Pagura G., Viel G., Nitti D. 2015. Increased and safer detection of nonrecurrent inferior laryngeal nerve after preoperative ultrasonography. The Laryngoscope 125:1743-7.

Kaisha W., Wobenjo A., Saidi H. 2011. Topography of the recurrent laryngeal nerve in relation to the thyroid artery, Zuckerkandl tubercle, and Berry ligament in Kenyans. Clinical anatomy (New York, N.Y.) 24:853-7.

Kandil E., Abdelghani S., Friedlander P., Alrasheedi S., Tufano RP., Bellows CF., Slakey D. 2011. Motor and sensory branching of the recurrent laryngeal nerve in thyroid surgery. Surgery 150:1222-7.

Lee M-S., Lee U-Y., Lee J-H., Han S-H. 2009. Relative direction and position of recurrent laryngeal nerve for anatomical configuration. Surgical and radiologic anatomy : SRA 31:649-55.

Lekacos NL., Tzardis PJ., Sfikakis PG., Patoulis SD., Restos SD. 1992. Course of the recurrent laryngeal nerve relative to the inferior thyroid artery and the suspensory ligament of Berry. International surgery 77:287-8.

De Luca L., Bergman JJ., Tytgat GN., Fockens P. 2000. EUS imaging of the arteria lusoria: case series and review. Gastrointestinal endoscopy 52:670-3.

Makay O., Icoz G., Yilmaz M., Akyildiz M., Yetkin E. 2008. The recurrent laryngeal nerve and the inferior thyroid artery--anatomical variations during surgery. Langenbeck's archives of surgery / Deutsche Gesellschaft für Chirurgie 393:681-5.

Maranillo E., Vazquez T., Quer M., Niedenführ MR., Leon X., Viejo F., Parkin I., Sanudo JR. 2008. Potential structures that could be confused with a nonrecurrent inferior laryngeal nerve: an anatomic study. The Laryngoscope 118:56-60.

Menck J., Grüber J., Lierse W. 1990. [Anterior approach to the cervical vertebrae and the location of the recurrent laryngeal nerve]. Der Unfallchirurg 93:384-6.

Moher D., Liberati A., Tetzlaff J., Altman DG. 2009. Preferred reporting items for systematic reviews and meta-analyses: the PRISMA statement. Annals of internal medicine 151:264-9, W64.

Monfared A., Gorti G., Kim D. 2002. Microsurgical anatomy of the laryngeal nerves as related to thyroid surgery. The Laryngoscope 112:386-92.

Moreau S., Goullet de Rugy M., Babin E., Salame E., Delmas P., Valdazo A. 1998. The recurrent laryngeal nerve: related vascular anatomy. The Laryngoscope 108:1351-3. 
366

367

368

369

370

371

372

373

374

375

376

377

378

379

380

381

382

383

384

385

386

387

388

389

390

391

392

393

394

395

396

397

398

399

400

401

402

403

404

405

406

Natsis K., Lazaridis N., Gkiouliava A., Didagelos M., Piagkou M. 2015. A retroesophageal right subclavian artery in association with a thyroid ima artery: case report, clinical impact and review of the literature. Folia morphologica.

Ngo Nyeki A-R., Njock L-R., Miloundja J., Evehe Vokwely J-E., Bengono G. 2015. Recurrent laryngeal nerve landmarks during thyroidectomy. European Annals of Otorhinolaryngology, Head and Neck Diseases.

Page C., Foulon P., Strunski V. 2003. The inferior laryngeal nerve: surgical and anatomic considerations. Report of 251 thyroidectomies. Surgical and radiologic anatomy : SRA 25:188-91.

Papadatos D. 1978. [Two anatomical observations of a non-recurrent laryngeal nerve (author's transl)]. Anatomischer Anzeiger 144:97-106.

Pradeep P V., Jayashree B., Harshita SS. 2012. A Closer Look at Laryngeal Nerves during Thyroid Surgery: A Descriptive Study of 584 Nerves. Anatomy research international 2012:490390.

Proye C., Dumont HG., Depadt G., Lagache G. 1982. [The "nonrecurrent" recurrent nerve danger in thyroid surgery. 15 cases]. Annales de chirurgie 36:454-8.

Raffaelli M., Iacobone M., Henry JF. 2000. The "false" nonrecurrent inferior laryngeal nerve. Surgery 128:1082-7.

Reed AF. 1943. The relations of the inferior laryngeal nerve to the inferior thyroid artery. The Anatomical Record 85:17-23.

Sasou S., Nakamura S., Kurihara H. 1998. Suspensory ligament of Berry: its relationship to recurrent laryngeal nerve and anatomic examination of 24 autopsies. Head \& neck 20:695-8.

Satoh S., Tachibana S., Yokoi T., Yamashita H. 2013. [Preoperative diagnosis of nonrecurrent inferior laryngeal nerve--usefulness of CT and ultrasonography]. Nihon Jibiinkoka Gakkai kaiho 116:793801.

Sciumè C., Geraci G., Pisello F., Li Volsi F., Facella T., Licata A., Modica G. 2005. [Non recurrent laryngeal nerve. Personal experience]. Il Giornale di chirurgia 26:434-7.

Serpell JW., Yeung MJ., Grodski S. 2009. The motor fibers of the recurrent laryngeal nerve are located in the anterior extralaryngeal branch. Annals of surgery 249:648-52.

Shao T., Yang W., Zhang T., Wang Y., Jin X., Li Q., Kuang J., Qiu W., Chu PG., Yen Y. 2010. A newly identified variation at the entry of the recurrent laryngeal nerve into the larynx. Journal of investigative surgery: the official journal of the Academy of Surgical Research 23:314-20.

Shindo ML., Wu JC., Park EE. 2005. Surgical anatomy of the recurrent laryngeal nerve revisited. Otolaryngology--head and neck surgery: official journal of American Academy of OtolaryngologyHead and Neck Surgery 133:514-9.

Silva AT da., Siqueira SL., Arruda M. 2013. Anatomic variation of the inferior laryngeal nerve: nonrecurrent form. Rev. bras. cir. cabeça pescoço 42.

Skandalakis JE., Droulias C., Harlaftis N., Tzinas S., Gray SW., Akin JT. 1976. The recurrent laryngeal nerve. The American surgeon 42:629-34.

Spartà C., Cossu ML., Fais E., Palermo M., Cossu F., Ruggiu M., Noya G. 2004. [Non-recurrent inferior laryngeal nerve: anatomy, frequency and surgical considerations]. Minerva chirurgica 59:555-61.

Stedman G. 1823. A singular distribution of some of the nerves and arteries of the neck and the top of the thorax. Edinb Med Surg J 19:564-565. 
407 408

409

410

411

412

413

414

415

416

417

418

419

420

421

422

423

424

425

426

427

428

429

430

431

432

433

434

435

436

437

438

439

440

441

442

443

\section{6}

437

38

39

Stewart GR., Mountain JC., Colcock BP. 1972. Non-recurrent laryngeal nerve. The British journal of surgery 59:379-81.

Sturniolo G., D’Alia C., Tonante A., Gagliano E., Taranto F., Grazia Lo Schiavo M., D'Alia C., Tonante A., Gagliano E., Taranto F., Lo Schiavo MG. 1999. The recurrent laryngeal nerve related to thyroid surgery. American journal of surgery 177:485-488.

Sunanda H., Tilakeratne S., De Silva K. 2010. Surgical anatomy of the recurrent laryngeal nerve; a crosssectional descriptive study. Galle Medical Journal 15.

Tang W-J., Sun S-Q., Wang X-L., Sun Y-X., Huang H-X. 2012. An applied anatomical study on the recurrent laryngeal nerve and inferior thyroid artery. Surgical and radiologic anatomy: SRA $34: 325-32$.

Toniato A., Mazzarotto R., Piotto A., Bernante P., Pagetta C., Pelizzo MR. 2004. Identification of the nonrecurrent laryngeal nerve during thyroid surgery: 20-year experience. World journal of surgery 28:659-61.

Wade JS. 1955. Vulnerability of the recurrent laryngeal nerves at thyroidectomy. The British journal of surgery 43:164-80.

Wang Y., Ji Q., Li D., Wu Y., Zhu Y., Huang C., Shen Q., Wang Z., Zhang L., Sun T. 2011. Preoperative CT diagnosis of right nonrecurrent inferior laryngeal nerve. Head \& neck 33:232-8.

Watanabe A., Kawabori S., Osanai H., Taniguchi M., Hosokawa M. 2001. Preoperative computed tomography diagnosis of non-recurrent inferior laryngeal nerve. The Laryngoscope 111:1756-9.

Watanabe A., Taniguchi M., Kimura Y., Ito S., Hosokawa M., Sasaki S. 2016a. Efficient, effective, safe procedure to identify nonrecurrent inferior laryngeal nerve during thyroid surgery. Head \& neck 38:573-7.

Watanabe A., Taniguchi M., Kimura Y., Ito S., Hosokawa M., Sasaki S. 2016b. Efficient, effective, safe procedure to identify nonrecurrent inferior laryngeal nerve during thyroid surgery. Head \& neck 38:573-7. DOI: 10.1002/hed.23932.

Yang J., Yan S., Gong Y., Zhu J., Li Z., Gong R. 2014. [The value of chest X-ray and cervical vascular ultrasound in predicting the presence of non-recurrent laryngeal nerves]. Sichuan da xue xue bao. Yi xue ban = Journal of Sichuan University. Medical science edition 45:1036-9. 


\section{TABLES}

445 Table 1 - Table of Included Studies

\begin{tabular}{|c|c|c|c|c|}
\hline Study & Country & Type & $\begin{array}{l}\text { \# of Right } \\
\text { RLNs }\end{array}$ & $\begin{array}{l}\text { \# of NRLN } \\
\text { (Prevalence) }\end{array}$ \\
\hline Ardito 2004 & Italy & IP & 1342 & $5(0.37 \%)$ \\
\hline Asgharpour 2012 & Spain & C & 143 & $1(0.70 \%)$ \\
\hline Barczynski 2015 & Poland & IP & 1250 & $9(0.72 \%)$ \\
\hline Beneragama 2006 & Australia & IP & 114 & $1(0.88 \%)$ \\
\hline Benouaich 2012 & France & C & 10 & $0(0 \%)$ \\
\hline Bula 2015 & Poland & IP & 1710 & $4(0.23 \%)$ \\
\hline Cai 2013 & China & IP & 783 & $4(0.51 \%)$ \\
\hline Campos 2000 & Brazil & $\mathrm{C}$ & 71 & $0(0 \%)$ \\
\hline Chiang 2012 & Taiwan & IP & 310 & $4(1.29 \%)$ \\
\hline Dolezel 2015 & Czech Republic & IR & 725 & $4(0.55 \%)$ \\
\hline Donatini 2013 & France & IR & 402 & $11(2.74 \%)$ \\
\hline Flament 1983 & France & $\mathrm{C}$ & 100 & $2(2 \%)$ \\
\hline Freschi 1994 & Italy & IP & 42 & $0(0 \%)$ \\
\hline Han 2015 & China & IR & 1056 & $6(0.57 \%)$ \\
\hline Henry 1988 & France & IR & 4921 & $31(0.63 \%)$ \\
\hline Hermans 2003 & Belgium & IP & 484 & $1(0.21 \%)$ \\
\hline Hong 2014 & Korea & IR & 2187 & $15(0.69 \%)$ \\
\hline Hunt 1968 & Australia & $\mathrm{C}$ & 77 & $1(1.30 \%)$ \\
\hline
\end{tabular}




\begin{tabular}{|c|c|c|c|c|}
\hline Iacobone 2015 & Italy & IP & 1477 & $17(1.15 \%)$ \\
\hline Kaisha 2011 & Kenya & C & 73 & $1(1.37 \%)$ \\
\hline Kandil 2011 & USA & IP & 162 & $0(0 \%)$ \\
\hline Lee 2009 & Korea & C & 70 & $0(0 \%)$ \\
\hline Lekacos 1992 & Greece & IR & 109 & $1(0.92 \%)$ \\
\hline Makay 2008 & Turkey & IP & 250 & $0(0 \%)$ \\
\hline Maranillo 2008 & Spain & C & 137 & $1(0.73 \%)$ \\
\hline Menck 1990 & Germany & C & 101 & $0(0 \%)$ \\
\hline Monfared 2002 & USA & C & 21 & $1(4.76 \%)$ \\
\hline Moreau 1998 & France & C & 17 & $0(0 \%)$ \\
\hline Ngo Nyeki 2015 & Switzerland & IP & 32 & $0(0 \%)$ \\
\hline Page 2003 & France & IP & 205 & $0(0 \%)$ \\
\hline Papadatos 1978 & France & $\mathrm{C}$ & 239 & $2(0.84 \%)$ \\
\hline Pradeep 2012 & India & IR & 324 & $1(0.31 \%)$ \\
\hline Proye 1982 & France & IR & 2490 & $15(0.60 \%)$ \\
\hline Raffaelli 2000 & France & IP & 656 & $3(0.46 \%)$ \\
\hline Reed 1943 & USA & C & 253 & $3(1.19 \%)$ \\
\hline Sasou 1998 & Japan & IR & 367 & $0(0 \%)$ \\
\hline Satoh 2013 & Japan & IR & 1561 & $11(0.70 \%)$ \\
\hline Sciumè 2005 & Italy & IR & 263 & $2(0.76 \%)$ \\
\hline Serpell 2009 & Australia & IP & 432 & $1(0.23 \%)$ \\
\hline
\end{tabular}




\begin{tabular}{|c|c|c|c|c|}
\hline Shao 2010 & China & IP & 1988 & $12(0.60 \%)$ \\
\hline Shindo 2005 & USA & IP & 149 & $1(0.67 \%)$ \\
\hline Silva 2013 & Brazil & $\mathrm{C}$ & 106 & $1(0.94 \%)$ \\
\hline Skandalakis 1976 & USA & $\mathrm{C}$ & 102 & $1(0.98 \%)$ \\
\hline Sparta 2004 & France & IP & 274 & $2(0.73 \%)$ \\
\hline Stewart 1972 & England & IP & 1776 & $6(0.34 \%)$ \\
\hline Sturniolo 1999 & Italy & IR & 141 & $0(0 \%)$ \\
\hline Sunanda 2010 & Sri Lanka & IP & 24 & $1(4.17 \%)$ \\
\hline Tang 2012 & China & $\mathrm{C}$ & 80 & $2(2.50 \%)$ \\
\hline Wade 1955 & England & $\mathrm{C}$ & 100 & $4(4 \%)$ \\
\hline Wang 2011 & China & IR & 290 & $9(3.10 \%)$ \\
\hline Watanabe 2001 & Japan & Imaging (CT) & 594 & $6(1.01 \%)$ \\
\hline Watanabe 2016 & Japan & IP & 730 & $4(0.55 \%)$ \\
\hline Yang 2014 & China & IR & 2251 & $28(1.24 \%)$ \\
\hline
\end{tabular}

446 RLN - Recurrent Laryngeal Nerve, NRLN - Non-Recurrent Laryngeal Nerve, C - Cadaveric, IP 447 Intraoperative Prospective, IR - Intraoperative Retrospective 
454 Table 2 - Type of Study Subgroup Analysis for Prevalence of a NRLN

\begin{tabular}{|l|l|l|l|l|}
\hline & $\begin{array}{l}\text { \# of studies (\# of } \\
\text { nerves) }\end{array}$ & $\begin{array}{l}\text { Prevalence of } \\
\text { NRLN: \% } \\
(\mathbf{9 5 \%} \text { CI) }\end{array}$ & $\mathbf{I}^{2}:$ \% (95\% CI) & $\begin{array}{l}\text { Cochrane's Q, } \\
\text { p-value }\end{array}$ \\
\hline Overall & $53(33571)$ & $0.7(0.6-0.9)$ & $42.5(20.2-58.6)$ & 0.001 \\
\hline Cadaveric & $17(1700)$ & $1.4(0.9-2.0)$ & $0(0-33.1)$ & 0.761 \\
\hline Intraoperative & $35(31277)$ & $0.7(0.5-0.8)$ & $50.6(27.1-66.5)$ & $<0.001$ \\
\hline $\begin{array}{l}\text { Intraoperative } \\
\text { (Prospective) }\end{array}$ & $21(14190)$ & $0.5(0.4-0.7)$ & $22.7(0-54.6)$ & 0.170 \\
\hline $\begin{array}{l}\text { Intraoperative } \\
\text { (Retrospective) }\end{array}$ & $14(17087)$ & $0.8(0.6-1.1)$ & $64.9(38.0-80.1)$ & $<0.001$ \\
\hline
\end{tabular}

456

457

458

459

460

461

462

463

464

465

466 
Table 3 - Geographical Subgroup Analysis for Prevalence of a NRLN

\begin{tabular}{|l|l|l|l|l|}
\hline & $\begin{array}{l}\text { \# of studies (\# of } \\
\text { nerves) }\end{array}$ & $\begin{array}{l}\text { Prevalence of } \\
\text { NRLN: \% } \\
\mathbf{9 5 \%} \text { CI) }\end{array}$ & $\mathbf{I}^{\mathbf{2}:} \% \mathbf{9 5 \%}$ CI) & $\begin{array}{l}\text { Cochrane's Q, } \\
\text { p-value }\end{array}$ \\
\hline Overall & $53(33571)$ & $0.7(0.6-0.9)$ & $42.5(20.2-58.6)$ & 0.001 \\
\hline Africa & $2(105)$ & $1.5(0.0-4.3)$ & $0.0(0.0-0.0)$ & 0.613 \\
\hline Asia & $15(12615)$ & $0.8(0.6-1.1)$ & $54.2(18.0-74.4)$ & 0.006 \\
\hline Europe & $25(17588)$ & $0.7(0.5-0.9)$ & $45.0(11.9-65.6)$ & 0.008 \\
\hline North America & $6(2463)$ & $0.7(0.2-1.4)$ & $38.4(0.0-75.5)$ & 0.149 \\
\hline Oceania & $3(623)$ & $0.6(0.0-1.5)$ & $14.1(0-91.1)$ & 0.312 \\
\hline South America & $2(177)$ & $0.9(0.0-2.5)$ & $0.0(0.0-0.0)$ & 0.449 \\
\hline
\end{tabular}

477 


\section{FIGURES}

480 Figure 1 - Normal Right Recurrent Laryngeal Nerve (A) and Right Non-Recurrent Laryngeal

481 Nerve in the Presence of an aberrant subclavian artery (B)
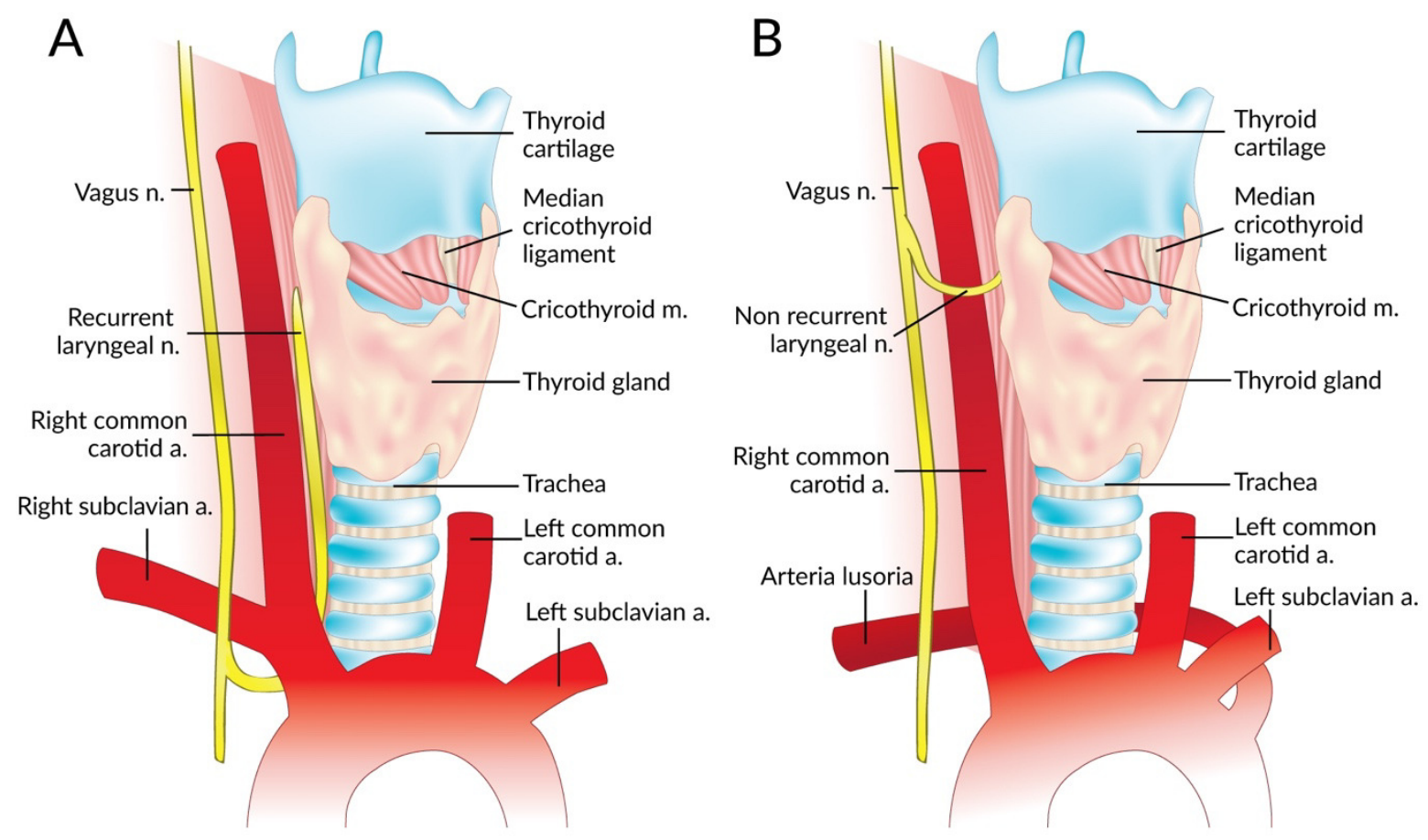

482

483

484

485

486

487 
491 Figure 2 - A Non-Recurrent Laryngeal Nerve Originating from the Vagus Nerve above (A) and 492 below (B) the Laryngotracheal Junction
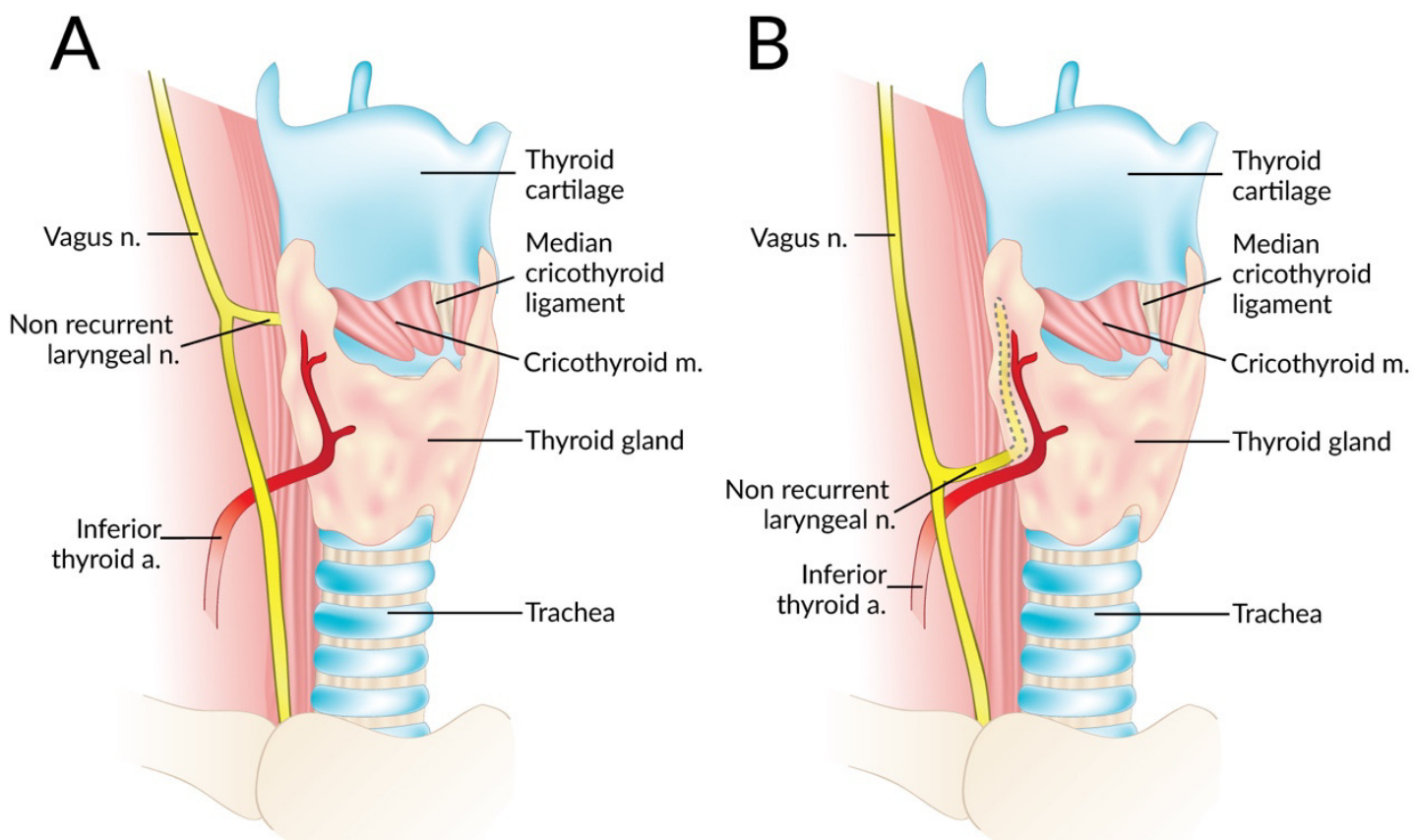

493

494

495

496

497

498

499

500

501

502 
503 Figure 3 - Flowchart of Study Search, Eligibility Assessment, and Inclusion

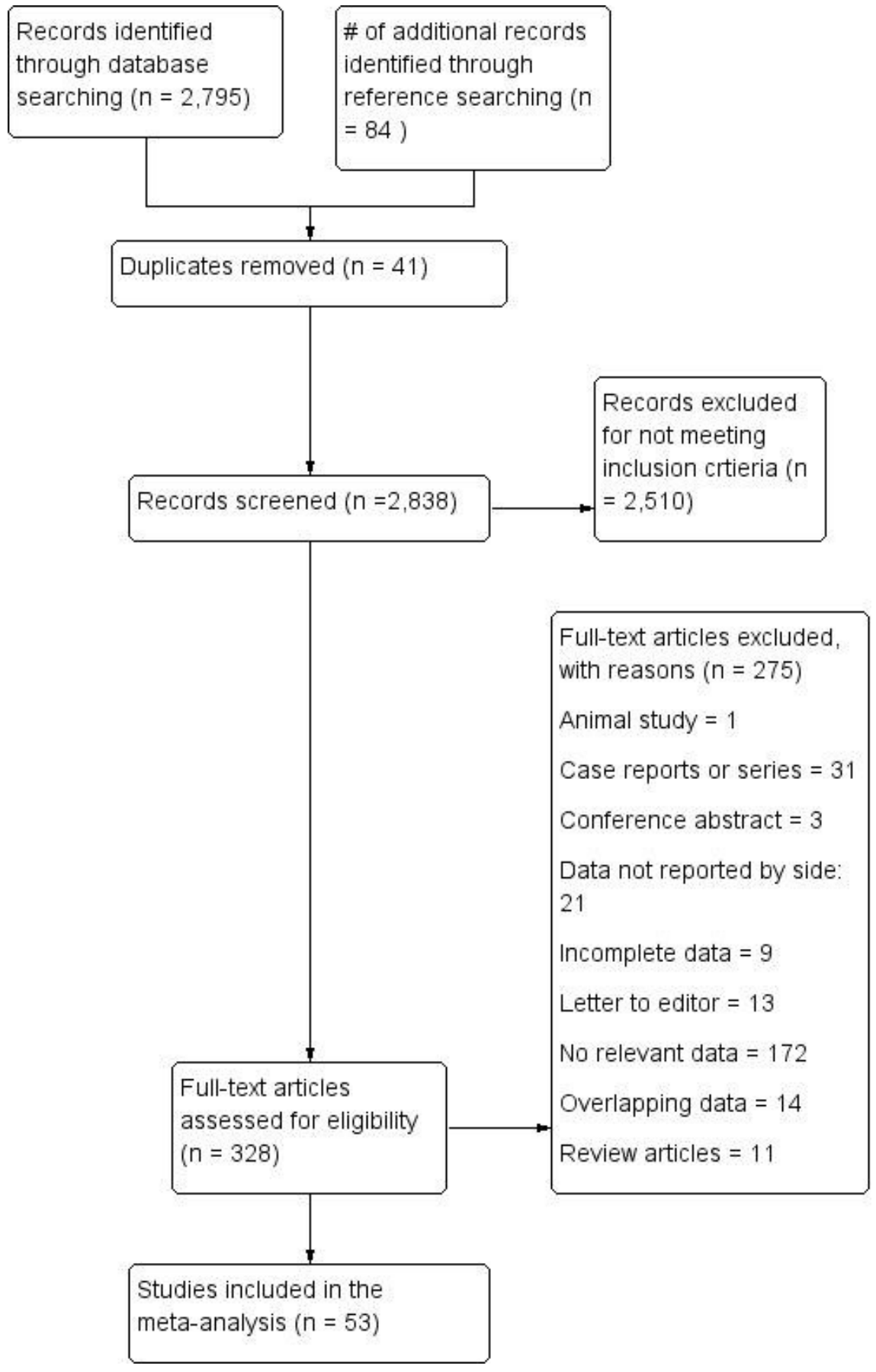


508 Figure 4 - Forest Plot for Pooled Prevalence of a Non-Recurrent Laryngeal Nerve

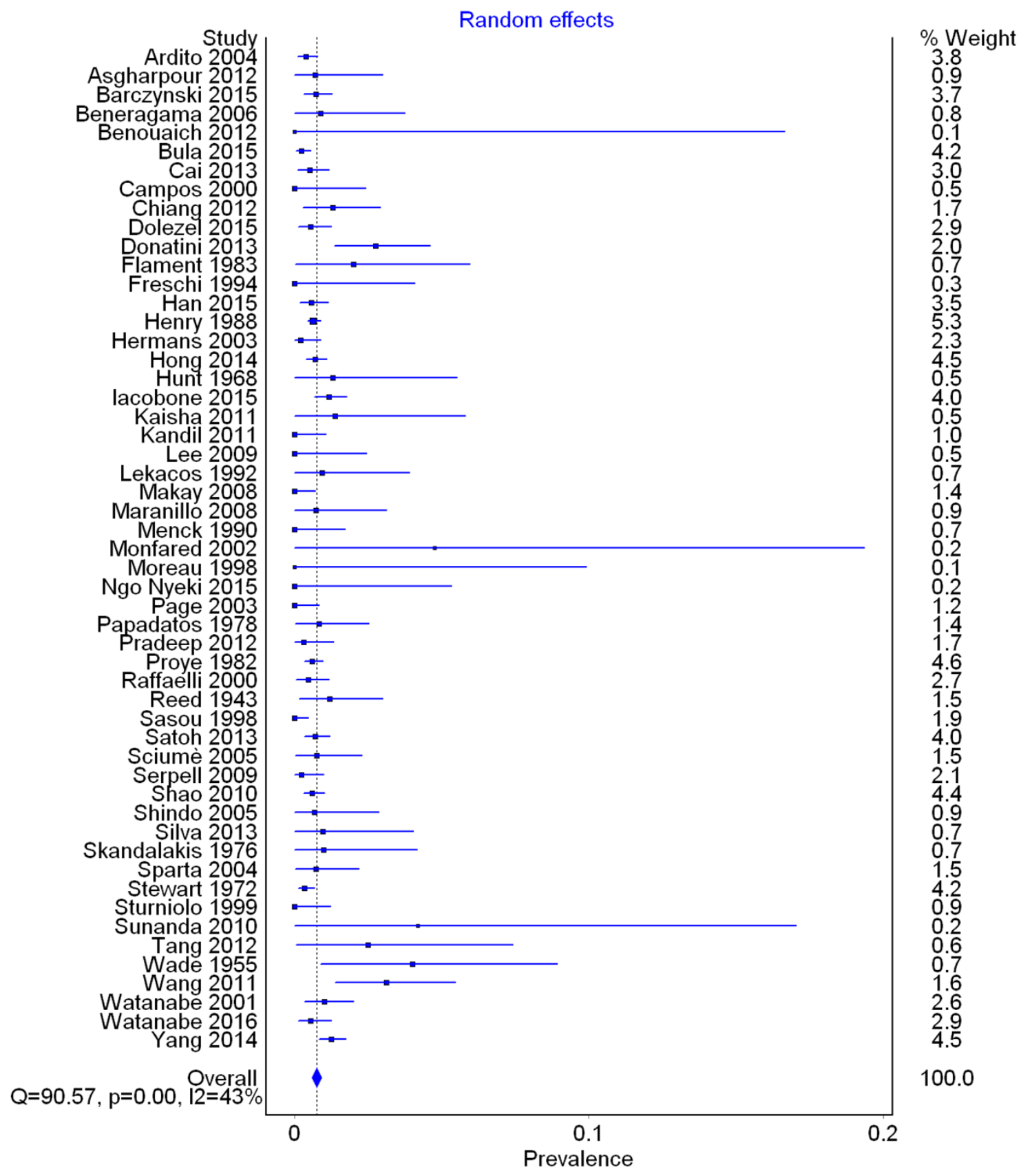

509

510 
512 Figure 5 - Looping Course of a Right Non-Recurrent Laryngeal Nerve

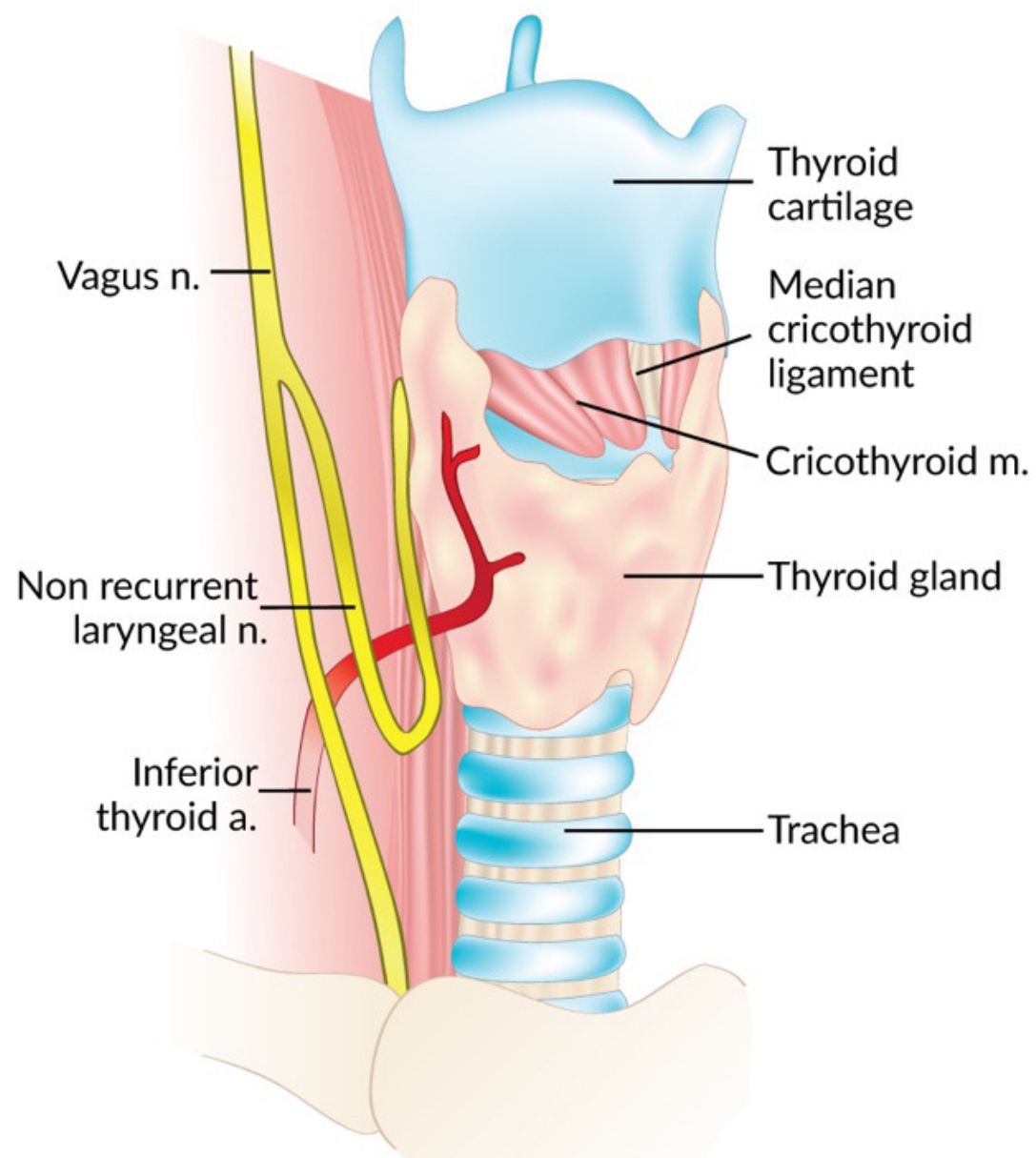

513

514

515

516

517

518 


\section{SUPPPLEMTAL INFORMATION LEGENDS}

520 Supplement Table 1 - Search Strategy for PubMed

521 Supplement Table 2 - PRISMA 2009 Checklist

522 Supplement Table 3 - Complete Study Data

523 